\title{
Vitamin D3-induced Neuroprotection is Dependent on System Xc Activity
}

\author{
Aditi Jani ${ }^{1}$, Stephanie Crockett ${ }^{4}$, Melinda Clarke ${ }^{1}$, Brittany Coleman ${ }^{1}$ and Brian Sims ${ }^{1,2,3 *}$ \\ ${ }^{1}$ University of Alabama at Birmingham, Department of Pediatrics, USA \\ ${ }^{2}$ University of Alabama at Birmingham, Department of Cell Biology, USA \\ ${ }^{3}$ Center for Glial Biology in Medicine, USA \\ ${ }^{4}$ University of California-Davis, Department of Comparative Pathology, USA
}

\begin{abstract}
Objective: Vitamin $D$ in the brain has been suggested as a potential neuroprotective agent. For vitamin $D$ to have the greatest effect, its receptor must be regulated or readily available. Vitamin $D_{3}$ is a pleiotropic hormone but one common neuroprotective pathway studied in our laboratory is glutathione regulation. Our objective was to investigate the intrinsic response of the vitamin D receptor under stress conditions, in in vitro preparations, and determine whether the neuroprotective effect of vitamin D is linked to the cystine-glutamate exchanger System Xc:
\end{abstract}

Methods: In vitro, mouse cortical neural stem cells were cultured and exposed to glutamate, as a model of cellular stress, with or without vitamin D supplementation. Western Blot analysis and immunocytochemistry was used to demonstrate the protective effect of Vitamin D3.

Main results: The vitamin D receptor was upregulated under stress conditions, and vitamin D supplementation was neuroprotective for neural stem cells. Vitamin $\mathrm{D}_{3}$-induced neuroprotection was attenuated by the addition of an inhibitor of System $\mathrm{Xc}^{-}$, a protein pivotal in glutathione biosynthesis.

Conclusion: Vitamin $D_{3}$ causes an increase in glutathione, suggesting that it has a major role in neuroprotection. Our results suggest that Vitamin D3-induced neuroprotection is regulated via System Xc- and glutathione biosynthesis.

Keywords: Neuroprotection; System Xc; Vitamin D; Vitamin D receptor

\section{Introduction}

Although the relationship between vitamin $\mathrm{D}_{3}$ and calcium is understood, recent research suggests that 1,25-dihydroxyvitamin $\mathrm{D}_{3}$ plays a role in brain development [1]. The vitamin $\mathrm{D}_{3}$ receptor (VDR) has been identified in brain and spinal cord neurons of developing fetal rats $[2,3,4]$, indicating that vitamin $\mathrm{D}_{3}$ must have some role in neurogenesis. Furthermore, vitamin $\mathrm{D}_{3}$ has been found to have a neuroprotective effect, as it regulates the production of nerve growth factor (NGF) and the expression of other neurotrophins [5]. Studies have also shown that VDR transcripts exist in rat oligodendrocytes, and VDR-positive cells were present in brain white matter [5]. Vitamin $\mathrm{D}_{3}$ increased the amount of transcripts coding for its own receptor, VDR, and also for NGF, further confirming a role in neurogenesis and protection [5].

Vitamin $\mathrm{D}_{3}$ was initially shown to increase NGF [6], but other trophic factors are also affected by Vitamin $\mathrm{D}_{3}$, including glial cell linederived neurotrophic factor [7] and neurotrophin [8]. These increases in neurotrophic factors have been correlated with neuroprotection $[9,10]$. Vitamin $\mathrm{D}_{3}$ has also been shown to modulate intracellular calcium and calcium-binding proteins to yield neuroprotection [11]. Other mechanisms imply that vitamin $\mathrm{D}_{3}$ has a role in neuroprotection by modulating glutathione, as shown by the inhibition of its synthesis with buthionine sulfoximine in dopaminergic neurons [12].

Glutathione biosynthesis is limited by the rate of cystine uptake. Glutathione is used for intracellular redox control and is dependent on intracellular cystine concentrations. System $\mathrm{Xc}^{-}$is a cystineglutamate exchanger that is coupled to equimolar exchanges of cystine. The cystine dimer is imported, where it is then reduced to cysteine and conjugated to glutamate and glycine to form glutathione (L$\gamma$-glutamyl-L-cysteinylglycine). System $\mathrm{Xc}^{-}$is an important protein in glutathione biosynthesis and its current regulation is incompletely understood. Here, we examine if vitamin $\mathrm{D}_{3}$ neuroprotection is linked to System Xc activity.

\section{Materials and Methods}

All equipment and chemicals used were from BioRad and Sigma Chemical Company (St. Louis, MO), respectively, unless otherwise stated.

\section{Cell culture}

Neural stem cells (catalog number SCR029) were obtained from Chemicon as Cryopreserved Mouse Cortical Neural Stem Cells. Plates coated overnight with $1 \mathrm{ml}$ of polyornithine $(10 \mathrm{mg} / \mathrm{ml})$ and laminin $(5 \mu \mathrm{g} / \mathrm{ml})$ were washed and either used for cell seeding immediately or stored at $-80^{\circ} \mathrm{C}$ until the time of experiment. Neural stem cells were cultured and passaged according to the manufacture's protocol. In brief, cells were grown in Neural Stem Cell Expansion Medium and supplemented with $20 \mathrm{ng} / \mathrm{ml}$ fibroblast growth factor-2, $20 \mathrm{ng} / \mathrm{ml}$ epidermal growth factor, and $2 \mathrm{~g} / \mathrm{ml}$ heparin. Cells were passaged every 3-5 days, or at $80 \%$ confluence, into T25-cm flasks at a 1:3 ratio. Differentiation was induced by media without supplemental growth factors after passage 3 .

*Corresponding author: Brian Sims MD, PhD, Department of Pediatrics Division of Neonatology, UAB, 619 20th Street South, 525 New Hillman Building, Birmingham, Alabama 35294, USA, Tel: (205) 975-5023; Fax: (205) 934-3100; E-Mail: bsims@peds.uab.edu

Received May 07, 2012; Accepted June 12, 2012; Published June 14, 2012

Citation: Jani A, Crockett S, Clarke M, Coleman B, Sims B (2012) Vitamin D3induced Neuroprotection is Dependent on System Xc Activity. J Stem Cell Res Ther 2:122. doi:10.4172/2157-7633.1000122

Copyright: (c) 2012 Jani A, et al. This is an open-access article distributed under the terms of the Creative Commons Attribution License, which permits unrestricted use, distribution, and reproduction in any medium, provided the original author and source are credited. 


\section{Glutathione assay}

The ApoGSH Glutathione Detection Kit (BioVision-Catalog K251-100) was used to measure sample glutathione levels. Using the enclosed protocol with this kit, samples were normalized for protein concentrations.

\section{Immunocytochemistry}

Primary antibodies for immunocytochemistry included actin (MAB1501-Chemicon) and VDR (ab8756-Abcam), and were used at 1:1000 overnight. Sections were stained by immunofluorescence using fluorescein isothiocyanate- (FITC) and cy3-conjugated secondary antibodies at 1:1000 for 2 hours. Nonspecific IgG and omission of primary antibody were used as controls for the staining specificity. To avoid bias, observers estimating immunocytochemistry staining were blind to treatment conditions and the same exposure time was used for all slides.

\section{Statistical analysis}

Statistical analysis was performed using the Student t-test comparing all samples to control. Data are presented as mean \pm standard deviation, with each experiment done in triplicate. Statistical significance was set at $\mathrm{p} \leq 0.05$. Analysis of variance was used to determine significance of experiments with multiple conditions.

\section{Results}

In several experiments, vitamin $\mathrm{D}_{3}$ has been shown to be neuroprotective and to increase VDR expression [13]. Currently, little is known about the response of VDR to stress. To understand the role of VDR, we used excess glutamate to determine if there was an increase in VDR as a function of glutamate concentration. VDR/actin protein ratios were normalized to control, as shown in Figure 1. The glutamate dose curve was $0,0.25,0.5,0.75,1$, and $3 \mathrm{mM}$. The significant concentrations were $0.75,1$ and $3 \mathrm{mM}$ (all $\mathrm{p} \leq 0.001$ ).

The increased VDR expression during stress could suggest that there is some protective pathway involved in VDR regulation. Such an increase in VDR could be a cellular preparation for increased vitamin D. Thus, vitamin D could be involved in protection. The mechanism behind cellular protection conferred by Vitamin D3 administration is unclear. One plausible mechanism is the production of the antioxidant glutathione. To examine this, we added vitamin $\mathrm{D}$ to the neural stem cells and examined glutathione production. Glutathione levels increased at 10 and $100 \mathrm{nM}$, a 4- and 5.7-fold increase, respectively (Figure 2A, $\mathrm{p} \leq 0.05$ )

One of the pivotal proteins involved in glutathione biosynthesis is System Xc, and its activity is involved in neuroprotection [14]. In Figure 2B, Western Blot analysis reveals an increase in System Xc protein levels under stressed conditions at 25, 45 and $65 \mathrm{nM}$ Vitamin D compared to control (Figure 3).

In the presence of toxic concentrations of glutamate at 1 and 10 $\mathrm{nM}$, vitamin $\mathrm{D}$ showed neuroprotective effects, but appeared toxic over $100 \mathrm{nM}$ (Figure 2A). The neuroprotective effect was attenuated by the addition of a potent inhibitor of System Xc', S4-carboxyphenylglycine, at $10 \mathrm{nM}$, suggesting that vitamin D's neuroprotective is linked to System Xc activity. To further quantitate the results we counted viable cells under stressed conditions with the addition of Vitamin D3. 100nM Vitamin D3 caused a decrease in cell viability correlating with the glutathione data seen. The most significant results were seen at 1 and $10 \mathrm{nM}$ Vitamin D3. Vitamin D3 at 1 and 10nM protected cells from cell death but when System Xc activity was inhibited at 1nM the protective effect was lost. Using a higher dose of Vitamin D3 at 10nM increased cell viability even in the presence of the System Xc inhibitor, S-CPG (Figure 4).

\section{Discussion}

Vitamin D has been shown to regulate its own receptor [13], but little is known concerning the role of VDR in the neuroprotective effects of vitamin $\mathrm{D}$. The present paper shows that the receptor responds directly to stress in vitro. Some of the neuroprotective properties of vitamin D include calcium homeostasis and trophic factor regulation. Here we demonstrate that there is a response to glutamate-induced stress. Such an increase in VDR could reflect either an association with death, or a potential mechanism that could be employed that may help the cell survive. Both scenarios are possible, and this may be dependent on what concentration of vitamin D is available to the cell.

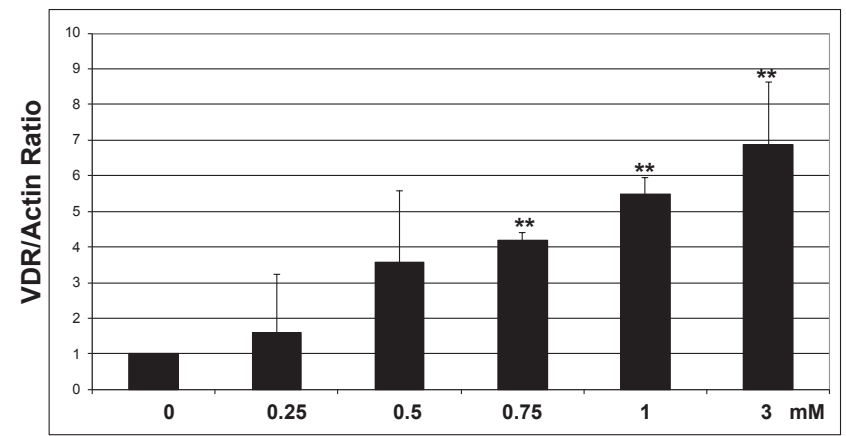

Figure 1: Effect of excitotoxicity on VDR Glutamate concentrations are 0 $0.25,0.5,0.75,1$, and $3 \mathrm{mM}$. Densitometric quantification of VDR concentration (normalized to actin) as listed. ${ }^{*} p \leq 0.05$ using the paired Student t-test.

A.

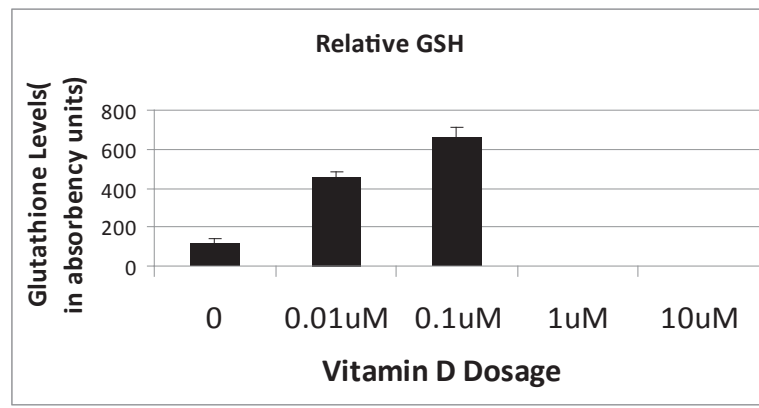

B.

\section{3mM glutamate}

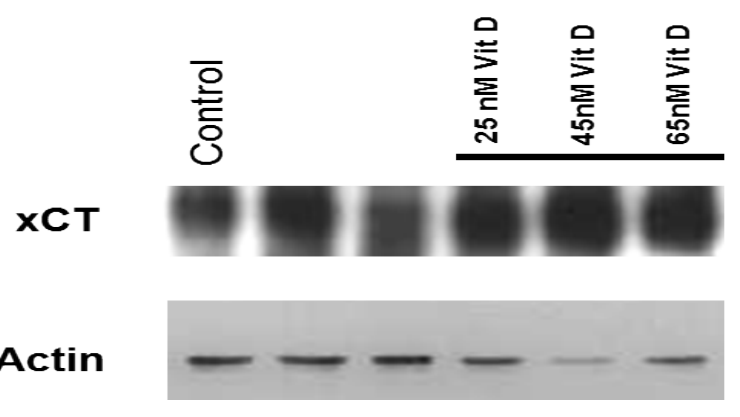

Figure 2: A. Relative glutathione levels in neural stem cells. Vitamin D concentrations used were $0,0.01,0.1,1$, and $10 \mu \mathrm{M}$. ${ }^{*} \mathrm{p} \leq 0.05$ using the paired Student t-test. B. Immunoblot of System XC (xCT) under multiple concentrations of Vitamin D. 


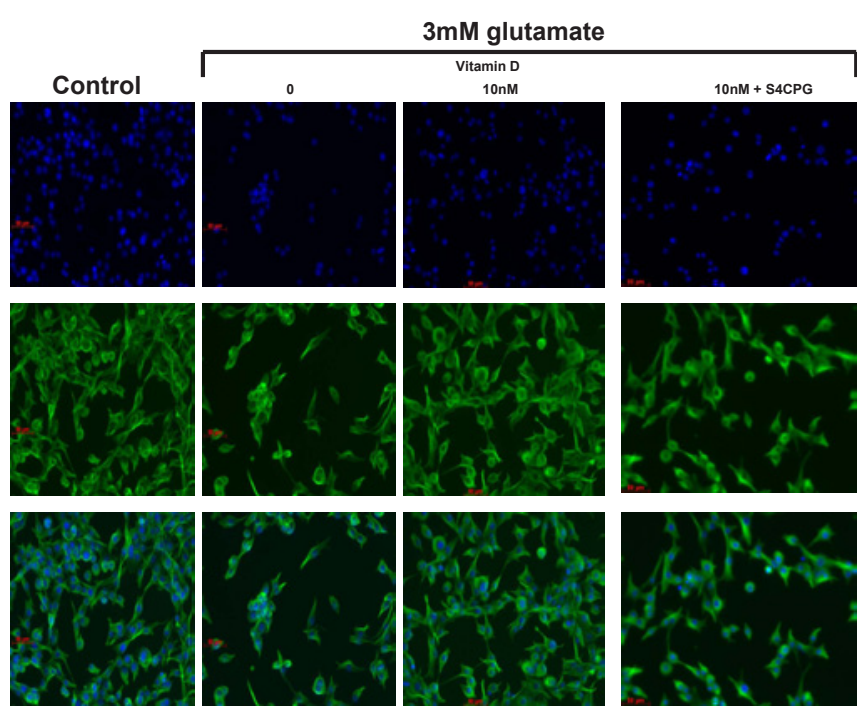

Figure 3: Immunocytochemistry of Neural Stem Cells in the presence of glutamate plus or minus Vitamin D3. Tubulin stained using FITC and nucle stained using Hoescht-dye.

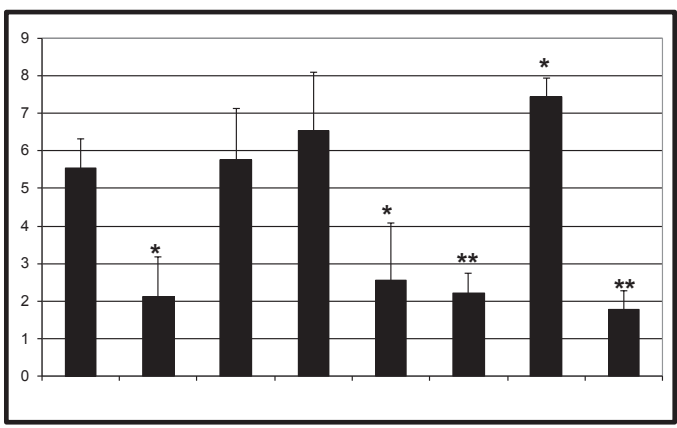

\begin{tabular}{|rcccccccc|}
\hline Glutamate(3mM) & - & + & + & + & + & + & + & + \\
Vitamin $\mathrm{D}(\mathrm{nM}) \mathrm{1}$ & - & - & + & - & - & + & - & - \\
10 & - & - & - & + & - & - & + & - \\
100 & - & - & - & - & + & - & - & + \\
$\mathrm{S} 4 \mathrm{CPG} \quad(250 \mu \mathrm{M})$ & - & - & - & - & - & + & + & + \\
\hline
\end{tabular}

Figure 4: Inhibition of System Xc- on vitamin D-induced neuroprotection. Cell viability relative to control. ${ }^{*} \mathrm{p} \leq 0.05$ in comparison to $3 \mathrm{mM}$ glutamate-treated cells using analysis of variance.

VDR showed a robust increase in expression with increasing concentrations of glutamate. The increase in VDR alone does not decrease the amount of cell death. Understanding this point led to the assumption that vitamin $\mathrm{D}$ supplementation may be needed to induce neuroprotection. Vitamin D proved to be neuroprotective at low nanomolar concentrations, and potentially toxic at higher concentrations. Novel to this paper is that glutathione biosynthesis was linked to vitamin D supplementation in neural stem cells. Inhibiting System $\mathrm{Xc}^{-}$attenuated the neuroprotective effect of vitamin $\mathrm{D}$, suggesting System $\mathrm{Xc}^{-}$regulation as a potential mechanism in vitamin D neuroprotection.

Collectively, these data suggest that the increase in VDR during stress may be a pathway that could be exploited and used for neuroprotection. The role of vitamin $\mathrm{D}$ in glutathione biosynthesis could prove to be an interesting area of investigation, and more importantly, its role in System $\mathrm{Xc}^{-}$regulation opens new avenues of neuroprotective research.

\section{References}

1. McGrath JJ, Feron FP, Burne TH, Mackay-Sim A, Eyles DW (2004) Vitamin D3 implications for brain development. J Steroid Biochem Mol Biol 89-90: 557-560.

2. Bidmon HJ, Stumpf WE (1992) Choroid plexus, ependyma and arachnoidea express receptors for vitamin D: differences between "seasonal" and "nonseasonal" breeders. Prog Brain Res 91: 279-283.

3. Prufer K, Jirikowski GF (1997) 1.25-Dihydroxyvitamin D3 receptor is partly colocalized with oxytocin immunoreactivity in neurons of the male rat hypothalamus. Cell Mol Biol (Noisy-le-grand) 43: 543-548.

4. Sutherland MK, Somerville MJ, Yoong LK, Bergeron C, Haussler MR, et al (1992) Reduction of vitamin D hormone receptor mRNA levels in Alzheimer as compared to Huntington hippocampus: correlation with calbindin-28k mRNA levels. Brain Res Mol Brain Res 13: 239-250.

5. Baas D, Prufer K, Ittel ME, Kuchler-Bopp S, Labourdette G, et al. (2000) Rat oligodendrocytes express the vitamin $\mathrm{D}(3)$ receptor and respond to 1,25-dihydroxyvitamin D(3). Glia 31: 59-68.

6. Wion D, MacGrogan D, Neveu I, Jehan F, Houlgatte R, et al. (1991) 1,25-Dihydroxyvitamin D3 is a potent inducer of nerve growth factor synthesis. J Neurosci Res 28: 110-114.

7. Naveilhan P, Neveu I, Wion D, Brachet P (1996) 1,25-Dihydroxyvitamin D3, an inducer of glial cell line-derived neurotrophic factor. Neuroreport 7: 2171-2175.

8. Neveu I, Naveilhan P, Baudet C, Brachet P, Metsis M (1994) 1,25-dihydroxyvitamin D3 regulates NT-3, NT-4 but not BDNF mRNA in astrocytes. Neuroreport 6: 124-126.

9. Wang Y, Chiang YH, Su TP, Hayashi T, Morales M, et al. (2000) Vitamin D(3) attenuates cortical infarction induced by middle cerebral arterial ligation in rats. Neuropharmacology 39: 873-880.

10. Riaz S, Malcangio M, Miller M, Tomlinson DR (1999) A vitamin D(3) derivative (CB1093) induces nerve growth factor and prevents neurotrophic deficits in streptozotocin-diabetic rats. Diabetologia 42: 1308-1313.

11. de Viragh PA, Haglid KG, Celio MR (1989) Parvalbumin increases in the caudate putamen of rats with vitamin D hypervitaminosis. Proc Natl Acad Sci USA 86: 3887-3890.

12. Shinpo K, Kikuchi S, Sasaki H, Moriwaka F, Tashiro K (2000) Effect of 1,25-dihydroxyvitamin $\mathrm{D}(3)$ on cultured mesencephalic dopaminergic neurons to the combined toxicity caused by L-buthionine sulfoximine and 1-methyl-4phenylpyridine. J Neurosci Res 62: 374-382.

13. Garcion E, Wion-Barbot N, Montero-Menei CN, Berger F, Wion D (2002) New clues about vitamin D functions in the nervous system. Trends Endocrino Metab 13: 100-105.

14. Crockett S, Clarke M, Reeves S, Sims B (2011) Cystine glutamate exchanger upregulation by retinoic acid induces neuroprotection in neural stem cells Neuroreport 22: 598-602 